\title{
PENGARUH PROMOSI MEDIA SITUS JUAL BELI ONLINE TERHADAP PENINGKATAN PENJUALAN PRODUK UKM
}

\author{
Oleh: \\ Erina Sovania ${ }^{1}$ \\ Irma Selliamanik ${ }^{2}$ \\ Program Studi Manajemen Pemasaran \\ IKPIA Perbanas \\ Email: \\ erinasovania9@gmail.com
}

\begin{abstract}
ABSTRAK
Produk UKM merupakan industri lokal skala kecil dan menengah yang harus secara intens didukung perkembangannya karena produk lokal ini dapat mengangkat taraf hidup masyarakat disuatu wilayah pinggiran kota besar atau pedesaan menjadi masyarakat yang mandiri. Penelitian ini bertujuan untuk membuka pandangan secara luas bahwa untuk produk UKM harus melakukan promosi penjualan secara luas agar produknya bisa terkenal dan penjualan dapat menembus pasar yang lebih luas lagi. Adapun penelitian yang dilakukan adalah dengan melakukan metode penelitian kuantitatif, dengan metode pengumpulan data melalui kuesioner dan wawancara melalui responden sebanyak 50 online shop yang ada di bukalapak.com. Data diolah dan dianalisis dengan menggunakan teknik analisis data Korelasi Pearson Product Moment (PPM) untuk mengetahui seberapa besar hubungan, Koefisiensi Determinan untuk mengetahui kontribusi dari variabel X terhadap variabel Y dan Uji Signifikansi untuk mengetahui dari Makna Hubungan di kedua variabel, dan regresi linear. Dari hasil penelitian ini diperoleh bahwasanya Promosi media situs jual beli online memiliki hubungan yang kuat serta memiliki pengaruh yang tinggi terhadap Peningkatan penjualan produk UKM. Dimana diperoleh korelasi PPM (hubungan) yang masuk dalam kriteria hubungan kuat, dan koefisiensi determinan memiliki pengaruh yang tinggi atau kuat, dan uji signifikansi dengan interpretasi memiliki makna hubungan yang berpengaruh.
\end{abstract}

Kata Kunci: Jual beli online, promo e-Commerce, peningkatan penjualan produk UKM 


\begin{abstract}
SME products are small and medium-sized local industries that must be intensely supported by their development as these local products can raise the standard of living of people in a large suburban or rural area into an independent community. This study aims to open the view widely that for SME products should conduct sales promotion widely so that the product can be famous and sales can penetrate the market more broadly. The research is done by conducting quantitative research methods, with data collection methods through questionnaires and interviews through the respondents of 50 online shop in www.bukalapak.com then data processed and analyzed by using data analysis techniques Pearson Product Moment (PPM) to know how big the relationship, Coefficient Determinant to know the contribution of variable $X$ to variable $Y$ and significance test to know from the meaning of relationship in both variables and linear regression. From the results of this stud, it was found that the promotion of media online (buying and selling site) has a strong relationship and has a high influence on the increase in sales of SME products. Where PPM correlation (relationship) is included in the criteria of strong relationships, and determinant coefficients have a high or strong influence, and significance tests with interpretations have meaningful influential relationships.
\end{abstract}

Keywords: Online shopping, e-Coomerce Promotions, Increasing sales of SME products

\title{
A. PENDAHULUAN
}

Tercatat pada Mei 2016 oleh Badan Pusat Statistik (BPS), jumlah pengangguran di Republik Indonesia mencapai angka 7,02 Juta Jiwa (5,81 persen dari jumlah penduduk). Idealnya, angka pengangguran sebuah negara berada di angka 3\% untuk menemukan supply dan demand dari jumlah pencari kerja dan jumlah kebutuhan tenaga kerja, jelas bahwasaat ini populasi penduduk dengan usia produktif lebih banyak daripada jumlah lapangan kerja yang tersedia. Hal ini seharusnya dapat memicu seseorang untuk menciptakan peluangnya sendiri dengan membuka bisnis.

Usaha kecil dan menengah (UKM) adalah salah satu bidang yang memberikan kontribusi yang segnifikan dalam memacu pertumbuhan ekonomi Indonesia. Hal ini dikarenakan daya serap UKM terhadap tenaga kerja yang sangat besar dan dekat dengan rakyat kecil (Kuncoro, 2008, Sripo, 2010). Masalah utama yang dihadapi oleh UKM adalah pemasaran (Hafsah, 2004; Kuncoro, 2008; Kurniawan, 2009; Supardi, 2009).

Pemasaran dengan metode konvensional memerlukan biaya tinggi, misalnya membuka cabang baru, ikut pameran, pembuatan dan penyebaran brosur dan sebagainya. Berkembangnya internet menjadi sarana yang efisien untuk membuka jalur pemasaran model baru bagi produk UKM. Di samping biayanya relatif murah, dengan memanfaatkan internet penyebaran informasi akan lebih cepat dan 
jangkauannya lebih luas(Supardi, 2009). Manfaat dan keuntungan lain menggunakan media $e$-commerceadalah untuk media promosi dalam rangka untuk meningkatkan volume penjualan, baik untuk penjualan online maupun konvensional (Jansen, 2006; Supardi, 2009). Di samping keuntungan tersebut, ternyata hasil beberapa penelitian menunjukkan bahwa efektivitas penggunaan media internete-commerce dalam mendongkrak peningkatan volume penjualan dan mempromosikan produk-produk industri cukup tinggi (Alexander, 2002; Supardi 2008; Wuwei 2009).

Berdasarkan data dari We Are Social (wearesocial.sg), pertumbuhan internet di Indonesia kian mengalami pertumbuhan yang pesat. Hingga awal Januari 2015, tercatat bahwa penetrasi internet di Indonesia mencapai nilai 72.700 .000 juta pengguna aktif dari keseluruhan populasi yaitu 255.500.000 (wearesocial.sg: 2015). Secara demografis, pengguna internet di Indonesia di dominasi oleh pengguna dengan usia 12-35 tahun atau sekitar $60 \%$ dari jumlah pengguna Internet. Dari segi geografis, 57\% pengguna internet yang kian pesat tersebut diperkirakan dapat mencapai 100 juta orang pengguna pada tahun 2015 (APJII, 2015). Dengan terus meningkatnya jumlah masyarakat yang memiliki akses terhadap internet, maka akan melihat peningkatan jumlah konsumen yang akan berbelanja online, dimana salah satunya adalah belanja melalui www.bukalapak.com. Diharapkan situs jual beli Bukalapak dapat menjadi alternatif media promosi bagi UKM sehingga dapat membantu meningkatkan penjualan produk atau jasanya tanpa mengeluarkan biaya promosi dalam jumlah besar.Tujuan dilakukannya penelitian ini adalah untuk mengetahui seberapa besar pengaruh promosi di Bukalapakterhadap peningkatan penjualan produk UKM melalui fasilitas media online yang ada saat ini.

\section{B. KAJIAN PUSTAKA}

\section{Promosi}

Pengertian promosi menurut Djaslim Saladin dan Yevis Marty Oesman (2002:123) : "Promosi adalah suatu komunikasi informasi penjual dan pembeli yang bertujuan untuk merubah sikap dan tinakah laku pembeli, yang sebelumnya tidak mengenal menjadi mengenal sehingga menjadi pembeli dan mengingat produk tersebut". Sedangkan pengertian promosi menurut Buchari Alma (2006:179) adalah : "Promosi adalah sejenis komunikasi yang memberi penjelasan dan meyakinkan calon konsumen mengenai barang dan jasa dengan tujuan untuk memperoleh perhatian, mendidik, mengingatkan dan meyakinkan calon konsumen".

Promosi merupakan alat komunikasi dan penyampaian pesan yang dilakukan baik oleh perusahaan maupun perantara dengan tujuan memberikan informasi mengenai produk, harga dan tempat. Informasi itu bersifat memberitahukan, membujuk, mengingatkan kembali kepada konsumen, para perantara atau kombinasi keduanya. 


\section{Situs Jual Beli Online (E-Commerce)}

Perdagangan elektronik atau yang disebut juga e-commerce, adalah penggunaan jaringan komunikasi dan komputer untuk melaksanakan proses bisnis. Pandangan populer dari e-commerce adalah penggunaan internet dan komputer dengan browser Web untuk membeli dan menjual produk. McLeod Pearson (2008:59).

Menurut Shely Cashman (2007:83) E-commerce atau kependekan dari elektronik commerce (perdagangan secara electronic), merupakan transaksi bisnis yang terjadi dalam jaringan elektronik, seperti internet. Siapapun yang dapat mengakses komputer, memiliki sambungan ke internet, dan memiliki cara untuk membayar barang-barang atau jasa yang mereka beli, dapat berpartisipasi dalam e-commerce.

Ada juga yang mengungkapkan bahwa berbelanja online merupakan proses pembelian barang/jasa oleh konsumen ke penjual realtime, tanpa pelayanan dan melalui internet.

Toko virtual ini mengubah paradigma proses membeli barang atau jasa dibatasi oleh tembok, pengecer, atau mall. Maksudnya kita tidakperlu bertemu dengan penjual/pembeli secara langsung, tidak perlu menemukan wujud "pasar" secara fisik, namun hanya dengan menghadap layar kita sudah dapat melakukan jual beli.

Salah satu media online yang digunakan oleh perusahaan sebagai media jual beli online, yakni situs website. Karakteristik website didefinisikan sebagai atribut yang dipertimbangkan konsumen dalam melakukan penilaian pada suatu online store. Karakteristik website diukur mmenggunakan lima dimensi yaitu:

a. Kenyamanan belanja. Dalam berbelanja di media online, konsumen mengharapkan agar mendapatkan kemudahan dalam melakukan pembelian.

b. Desain situs, situs dengan desain yang menarik akan lebih disukai dan di minati oleh konsumen. Hal ini menunjukkan bahwa perusahaan harus memperhatikan tampilan situs agar lebih menarik.

c. Informatif, informasi di dalam situs web harus memuat informasi yang detail baik mengenai produk maupun cara pemakaian.

d. Keamanan, selain penjual harus dapat menjaga privasi dari pembeli, pihak penjual juga harusdapat memberikan jaminan bahwa transaksi berlangsung secara aman.

e. Komunikasi. Dalam proses pembelian, konsumen terkadang memerlukan informasi secara langsung dari pihak penjual, oleh karena ini nomor telepon maupun alamat penjual harus mudah dihubungi.

\section{METODE PENELITIAN}

\section{Jenis Penelitian}

Dalam penelitian ini, penulis melakukan metode penelitian kuantitatif, dengan metode pengumpulan data melalui kuesioner dan wawancara. Wawancara yang dilakukan adalah dengan tanya jawab dan berkomunikasi secara langsung objek yang diteliti atau responden dalam rangka untuk memperkuat keabsahan 
data peneliti, dalam hal ini adalah para pemilik toko-toko online shop di bukalapak.com yang menjual pakaian, jilbab, makanan, kerajinan tangan dan total dalam penelitian ini adalah 50 responden pemilik online shop.

Karena penelitian ini merupakan penelitian korelasional, maka untuk mendeteksi sejauh mana variasi pada suatu faktor berkaitan dengan variasi pada satu atau lebih faktor lain berdasarkan koefisien korelasi, variabel yang digunakan dalam penelitian ini adalah:

1. Variable Independen (variable bebas - x), dalam penelitian ini variable bebasnya adalah "Promosi melalui Media Situs Jual Beli Online"

2. Variabel Dependen (variable terikat- y). Dalam penelitian ini untuk variable terikat terdapat pada "Peningkatan Penjualan"

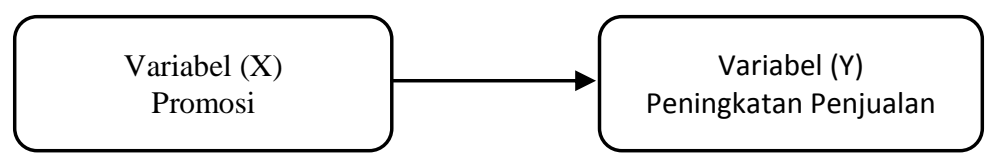

Gambar 1.

Paradigma Penelitian

\section{Definisi Operasionalisasi Variabel}

Operasionalisasi variabel diperlukan guna menentukan jenis dan indikator dari variabel-variabel yang terkait dalam penelitian ini. Disamping itu, operasionalisasi variabel bertujuan untuk menentukan skala pengukuran dari masing-masing variabel, sehingga pengujian hipotesis dengan menggunakan alat bantu dapat dilakukan dengan tepat. Secara lebih rinci operasionalisasi variabel dalam penelitiannya ini dapat dilihat pada tabel berikut:

Tabel 2

Operasionalisasi Variabel

\begin{tabular}{|c|c|c|}
\hline VARIABEL & DIMENSI & INDIKATOR \\
\hline \multirow{3}{*}{$\begin{array}{l}\text { Variabel Bebas }(\mathbf{x}) \\
\text { Promosi melalui media } \\
\text { situs jual beli online }\end{array}$} & - $\quad$ Performa Produk yang dijual & $\begin{array}{ll}\text { - } & \text { Kualitas produk } \\
\text { - } & \text { Harga produk } \\
\text { - } & \text { Pengiriman produk }\end{array}$ \\
\hline & - $\quad$ Program Promosi & $\begin{array}{ll}- & \text { Terdapat penawaran harga } \\
\text { special } \\
\text { - } & \text { Promo bebas ongkir } \\
\end{array}$ \\
\hline & - $\quad$ Interaksi & $\begin{array}{ll}\text { - } & \text { Tersedia forum tanya jawab } \\
\text { - } & \text { Informasi nomor kontak } \\
& \text { yang dapat dihubungi }\end{array}$ \\
\hline $\begin{array}{c}\text { Variabel Terikat (y) } \\
\text { Peningkatan Penjualan }\end{array}$ & $\begin{array}{l}\text { - } \quad \text { Kegiatan yang dilakukan untuk } \\
\text { menyampaikan barang kepada } \\
\text { konsumen }\end{array}$ & $\begin{array}{ll}- & \text { Jumlah Pengunjung } \\
- & \text { Jumlah Pembeli } \\
- & \text { Jumlah penjualan/omset }\end{array}$ \\
\hline
\end{tabular}




\section{HASIL DAN PEMBAHASAN}

\section{Hasil Penelitian}

Berdasarkan hasil survey terhadap 50 responden, dapat dideskripsikan melalui Nama online shop, Kategori usaha, Lokasi, Total pelanggan, Produk yang dilihat, Terjual dan Peminat sebagaimana yang tertuang pada tabel berikut.

Tabel 3: Rekap Online shop

\begin{tabular}{|c|c|c|c|c|c|c|c|c|}
\hline No & $\begin{array}{c}\text { Nama } \\
\text { Online shop }\end{array}$ & $\begin{array}{c}\text { Kategori } \\
\text { Usaha }\end{array}$ & Lokasi & $\begin{array}{c}\text { Total } \\
\text { Pelanggan }\end{array}$ & $\begin{array}{c}\text { Produk } \\
\text { Dilihat }\end{array}$ & Terjual & Peminat & $\begin{array}{c}\text { Harga } \\
(\mathbf{R p})\end{array}$ \\
\hline 1 & Bee & Ciput jilbab & Bandung & 121 & 27,290 & 1,686 & 348 & 62,500 \\
\hline 2 & GrosirHij & Cadar Niqab & Jepara & 1,643 & 6,396 & 111 & 374 & 4,900 \\
\hline 3 & LuckyStore & Jilbab Segi Empat & Tasikmalaya & 828 & 153,244 & 2,682 & 2,150 & 13,900 \\
\hline 4 & StoreBL & Jilbab Pashmina & Bandung & 1,900 & 201,474 & 5,399 & 3,387 & 23,400 \\
\hline 5 & RivalMu & Hijab Khimar Latifa & Garut & 552 & 15,952 & 187 & 180 & 39,000 \\
\hline 6 & ForeverJa & Hijab Instan & Jakarta & 10,523 & 95,431 & 796 & 918 & 49,500 \\
\hline 7 & AdiAdha & Jilbab & Garut & 1,475 & 20,184 & 570 & 346 & 29,800 \\
\hline 8 & AbiShop & Jilbab & Tasikmalaya & 384 & 18,449 & 886 & 347 & 20,000 \\
\hline 9 & Milyar & Jilbab & Bandung & 2,812 & 17,704 & 375 & 453 & 37,000 \\
\hline 10 & Kartaja & Jilbab & Semarang & 549 & 137,456 & 3,903 & 1,312 & 11,500 \\
\hline 11 & AyuStore & Baju & Bandung & 1,561 & 50,854 & 554 & 741 & 117,500 \\
\hline 12 & Rajagrosir & Baju & Bandung & 3,040 & 48,759 & 281 & 1,051 & 55,000 \\
\hline 13 & MorryFas & Baju & Bogor & 272 & 527,159 & 415 & 908 & 60,500 \\
\hline 14 & Hijab Store & Baju & Cimahi & 2,561 & 44,187 & 245 & 560 & 63,000 \\
\hline 15 & CheapCoz & Baju & Jakarta & 165 & 105,896 & 533 & 560 & 78,000 \\
\hline 16 & AlequaS & Baju & Bandung & 65 & 21,067 & 2,501 & 1,014 & 50,000 \\
\hline 17 & Shinfashion & Baju & Tangerang & 1,750 & 125,978 & 1,657 & 3,222 & 58,000 \\
\hline 18 & BatikSolo & Batik & Solo & 356 & 49,021 & 204 & 756 & 156,800 \\
\hline 19 & JogjaBatik & Batik & Bantul & 1,887 & 12,476 & 319 & 300 & 57,500 \\
\hline 20 & CadColl & Batik & Solo & 2,832 & 184,465 & 282 & 932 & 91,000 \\
\hline 21 & BatikMan & Batik & Batang & 107 & 26,616 & 342 & 348 & 34,000 \\
\hline 22 & Hariyanto & Batik & Solo & 263 & 21,381 & 218 & 284 & 150,000 \\
\hline 23 & FaxxSouvenir & Souvenir gunting kuku & Ciamis & 546 & 5,463 & 8,654 & 200 & 900 \\
\hline 24 & BonekaBandung & Souvenir/boneka & Bandung & 603 & 22,661 & 925 & 568 & 10,000 \\
\hline 25 & SouvenirMurah & Souvenir gantungan & Bandung & 672 & 4,763 & 10,593 & 119 & 600 \\
\hline 26 & SouvenirTahlilan & souvenir Peci & Surabaya & 235 & 11,882 & 4,779 & 317 & 1,900 \\
\hline 27 & Anekamainantas & Souvenir tas & Jakarta & 156 & 15,346 & 250 & 233 & 70,000 \\
\hline 28 & Oleh2khasbali & Makanan (pai Bali) & Denpasar & 50 & 8,558 & 213 & 371 & 125,000 \\
\hline 29 & Kagumipil & Makanan (kripik Lampung) & Jakarta & 79 & 129 & 352 & 3 & 16,000 \\
\hline 30 & ItabilaSh & Makanan Bolen) & Cimahi & 450 & 4,361 & 105 & 120 & 55,000 \\
\hline 31 & BkenzS & Makanan (sambal) & Surabaya & 56 & 4,349 & 822 & 249 & 26,000 \\
\hline 32 & Cahyono & Makanan (mozarella) & Surabaya & 27 & 1,875 & 90 & 36 & 100,000 \\
\hline 33 & MyShopping & Boneka & Jakarta & 736 & 37,562 & 408 & 1,109 & 72,300 \\
\hline 34 & Miyato & Boneka & Rembang & 109 & 54,466 & 90 & 18 & 90,000 \\
\hline
\end{tabular}




\begin{tabular}{|c|l|l|l|c|c|c|c|c|}
35 & Bintangarga & Boneka & Purwakarta & 60 & 94,558 & 432 & 832 & 90,300 \\
\hline 36 & RajaBoneka & Boneka & Purwakarta & 270 & 22,671 & 262 & 398 & 99,000 \\
\hline 37 & Adam & Boneka & Bekasi & 95 & 13,151 & 625 & 259 & 13,800 \\
\hline 38 & Philo & Handmade (tas kulit) & Garut & 292 & 2,812 & 15 & 43 & 249,000 \\
\hline 39 & PoetraGems & Cincin batu lokal & Bogor & 3,818 & 25,454 & 204 & 560 & 120,000 \\
\hline 40 & Bintang & Tas lokal & Jakarta & 8,077 & 92,217 & 600 & 1,392 & 79,800 \\
\hline 41 & Aulia & Tas lokal & Jakarta & 516 & 52,524 & 405 & 1,074 & 100,000 \\
\hline 42 & Chaa & Tas lokal & Bandung & 1,816 & 53,383 & 285 & 569 & 55,000 \\
\hline 43 & Push & Tas local & Bandung & 1,481 & 430,406 & 1,430 & 4,220 & 75,000 \\
\hline 44 & Kobe & Tas local & Bandung & 1,597 & 46,127 & 401 & 994 & 28,600 \\
\hline 45 & Supplie Tas & Tas local & Tangerang & 1,877 & 91,793 & 1,372 & 1,987 & 36,000 \\
\hline 46 & Berkah & Bibit tanaman & Indramayu & 64 & 20,212 & 1,058 & 409 & 15,000 \\
\hline 47 & Benih & Bibit tanaman & Depok & 1,415 & 119,469 & 1,289 & 3,736 & 35,000 \\
\hline 48 & UDMitra & Bibit tanaman & Banyuwangi & 25 & 1,107 & 563 & 12 & 184,000 \\
\hline 49 & Peerina & Bibit tanaman & Cilegon & 2,043 & 19,212 & 790 & 882 & 10,000 \\
\hline 50 & Wae & Bibit tanaman & Yogyakarta & 1,499 & 16,085 & 1,032 & 525 & 14,000 \\
\hline
\end{tabular}

Dari data diatas diperoleh bahwa 50 toko tersebut telah berhasil melakukan penjualan produknya di situs jual beli online yaitu untuk 1 item produk. Online shop ini berhasil memasarkan produknya lintas daerah, dimana toko online shop ini terdiri dari berbagai macam wilayah yang bukan hanya di area Jakarta dan sekitarnya.

Dari data diatas, selanjutnya dilakukan pengolahan data dengan menganalisa melalui:

1. Korelasi Pearson Product Moment (PPM) untuk mengetahui seberapa besar hubungan

2. Koefisiensi Determinan untuk mengetahui kontribusi dari variabel $\mathrm{X}$ terhadap variabel $Y$

3. Uji Signifikansi untuk mengetahui dari Makna Hubungan, dan Regresi Sederhana untuk proses memperkirakan secara sistematis tentang apa yang paling mungkin terjadi berdasarkan informasi yang ada

\section{Pembahasan}

Untuk mengetahui sejauh mana pengaruh promosi melalui media situs jual beli online terhadap peningkatan penjualan produk UKM, maka digunakanlah alat statistik yang dapat menguatkan hasil perhitungan analisa, berikut ini tabel rekap atas perhitungan dan analisa dari penelitian ini yaitu sebagai berikut:

Tabel 4: Hasil Pengohan Data

\begin{tabular}{cccc}
\hline $\begin{array}{c}\text { Korelasi } \\
\text { PPM }\end{array}$ & $\begin{array}{c}\text { Koefisiensi } \\
\text { Determinan }\end{array}$ & $\begin{array}{c}\text { Uji } \\
\text { Signifikansi }\end{array}$ & Regresi \\
\hline \hline 0.75 & $57 \%$ & 9.805 & $\mathrm{y}=0.5467 \mathrm{x}-3.4702$ \\
\hline
\end{tabular}


Tabel 5: Interpretasi Hasil Penelitian

\begin{tabular}{ccc}
\hline $\begin{array}{c}\text { Korelasi PPM } \\
\text { (Hubungan) }\end{array}$ & $\begin{array}{c}\text { Koefisiensi Determinan } \\
\text { (Kontribusi X ke Y) }\end{array}$ & $\begin{array}{c}\text { Uji Signifikansi } \\
\text { (Makna Hubungan) }\end{array}$ \\
\hline \hline Kriteria Hubungan Kuat & Pengaruh Tinggi atau Kuat & Berpengaruh \\
\hline
\end{tabular}

Berikut ini penjabarannya:

\section{Korelasi Pearson Product Moment (PPM)}

Perhitungan ini dilakukan untuk mencari tahu dan menyatakan ada atau tidaknya hubungan antara variabel $\mathrm{X}$ dengan variabel $\mathrm{Y}$. Dari data yang telah dijabarkan dan dirangkum diatas yaitu Promosi di situs jual beli online dengan peningkatan penjualan produk, untuk hubungan antara Variabel X dan Y korelasi atau hubungannya adalah "Kuat". Dimana nilai korelasi PPM yang diperoleh adalah "0.75". Seperti yang disampaikan Sugiyono (2007) pedoman untuk memberikan interpretasi koefisien korelasi sebagai berikut:

- $0,00-0,199$ : sangat rendah

- $0,20-0,399$ : rendah

- $0,40-0,599$ : sedang

- $0,60-0,799$ : kuat

- $0,80-1,000$ : sangat kuat

Sehingga hasil dari penelitian korelasi PPM diatas, untuk Promosi di situs jual beli online memiliki hubungan yang kuat untuk memperoleh peningkatan penjualan produk UKM.

\section{Koefisien Determinasi}

Pada intinya mengukur seberapa jauh kemampuan model dalam menerangkan variasi variabel dependen. Jika kurang dari 50\%, maka dapat dikatakan variabel dalam penelitian tersebut hanya mampu menjelaskan sebesar kurang dari $50 \%$ dan sisanya dijelaskan oleh faktor lain. Seperti dikemukakan oleh Guilford yang dikutip oleh Supranto (2001: 227) adalah sebagai berikut:

Tabel 6.

\section{Kategori Koefisien Determinasi}

\begin{tabular}{c|l}
\hline Pernyataan & \multicolumn{1}{c}{ Keterangan } \\
\hline \hline$>4 \%$ & Pengaruh Rendah Sekali \\
$5 \%-16 \%$ & Pengaruh Rendah Tapi Pasti \\
$17 \%-49 \%$ & Pengaruh Cukup Berarti \\
$50 \%-81 \%$ & Pengaruh Tinggi atau Kuat \\
$>80 \%$ & Pangaruh Tinggi Sekali
\end{tabular}


Dari hasil perhitungan seperti yang tercantum dalam Tabel 4, disebutkan bahwa Promosi di situs jual beli online yang mana variabel $\mathrm{X}$ mengkontribusi pengaruh variabel $\mathrm{Y}$ "Tinggi atau Kuat", dengan nilai 0.57 atau dikonversikan ke persentase menjadi $57 \%$.

\section{Uji Signifikansi}

Uji ini dilakukan untuk mengetahui makna hubungan dari variabel $\mathrm{X}$ dengan variabel $\mathrm{Y}$, dengan menggunakan statistic Uji-t. Nilai signifikansi dari suatu hipotesis adalah nilai kebenaran dari hipotesis yang diterima atau ditolak. Peneliti menggunakan angka signifikansi sebesar 0,05. Angka signifikansi sebesar 0,05 mempunyai pengertian bahwa tingkat kepercayaan untuk memperoleh kebenaran dalam penulisan ini adalah sebesar 95\%. Jika angka signifikansi sebesar 0,05, maka tingkat kepercayaan adalah sebesar 95\%. $t_{\text {tabel }}$ yang digunakan dalam menguji $t_{\text {hitung }}$ atau uji signifikansi ini adalah dengan Derajat Kebebasan (df) yaitu n-2, dimana jumlah responden yaitu 50-2 adalah total 48, sehingga untuk $t_{\text {tabel }}$ adalah 1.677 .

Kriteria dari hasil penelitian yang dilakukan diperoleh $t_{\text {hitung: }}$

- Jika $t_{\text {hitung }}>\mathrm{t}_{\text {tabel }}$ pada $\propto=5 \%$ maka $\mathrm{H}_{0}$ ditolak dan $\mathrm{H}_{1}$ diterima (berpengaruh).

- Jika $\mathrm{t}_{\text {hitung }}<\mathrm{t}_{\text {tabel }}$ pada $\propto=5 \%$ maka $\mathrm{H}_{0}$ diterima dan $\mathrm{H}_{1}$ ditolak (tidak berpengaruh).

Hasil penghitungan yang diperoleh adalah $t_{\text {hitung }}$ sebesar 9.805 lebih besar dari $t_{\text {tabel }}$ yaitu 1.677, atau dengan kriteria penilaian $t_{\text {hitung }}>t_{\text {tabel }}$ maka $\mathrm{H}_{0}$ ditolak dan $\mathrm{H}_{1}$ diterima (berpengaruh). Berikut ini grafik dari regresi linearnya:

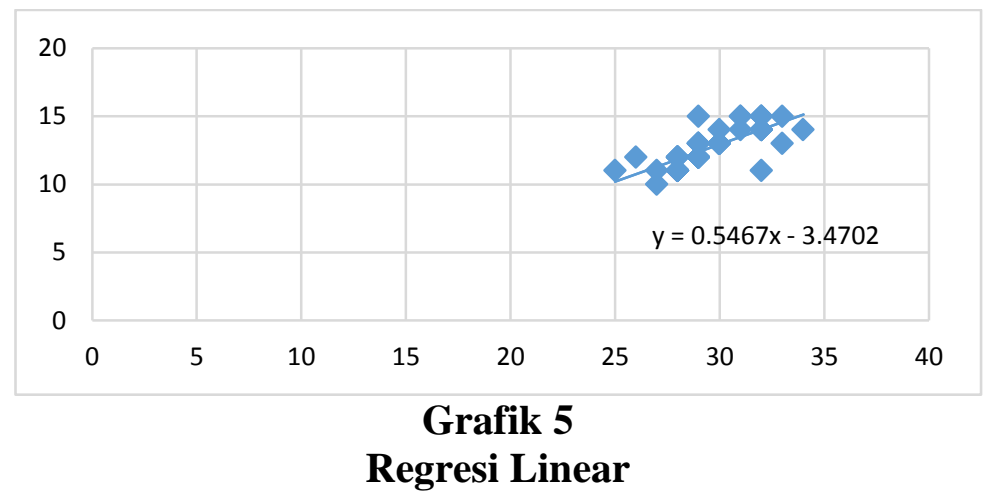

Tidak ada alasan lagi bahwa yang bisa menikmati kecanggihan teknologi hanyalah untuk segelitir orang dan yang hanya berada di wilayah kota besar. Saat ini, masyarakat yang tinggal di pedesaan sudah dapat memanfaatkan internet khususnya dalam memberdayakan usaha menjual produk UKM atau produk rumahan dengan lebih luas lagi dengan cara berpromosi di situs jual beli online.

Dapat dilihat data dibawah ini: 
Tabel 7.

Online shop, Lokasi, Total Pelanggan, Produk dilihat, Peminat, Harga, Omzet, Estimasi Target

\begin{tabular}{|c|c|c|c|c|c|c|c|c|}
\hline $\begin{array}{c}\text { Nama } \\
\text { Online shop }\end{array}$ & Lokasi & $\begin{array}{c}\text { Total } \\
\text { Pelanggan }\end{array}$ & $\begin{array}{l}\text { Produk } \\
\text { Dilihat }\end{array}$ & Terjual & Peminat & $\begin{array}{c}\text { Harga } \\
\text { (Rp) }\end{array}$ & Omzet & $\begin{array}{c}\text { Estimasi } \\
\text { Target } \\
(10 \%) \\
\end{array}$ \\
\hline Responden 1 & Bandung & 121 & 27,290 & 1,686 & 348 & 62,500 & $10105,375,000$ & $2,175,000$ \\
\hline Responden 2 & Jepara & 1,643 & 6,396 & 111 & 374 & 4,900 & 543,900 & 183,260 \\
\hline Responden 3 & Tasikmalaya & 828 & 153,244 & 2,682 & 2,150 & 13,900 & $37,279,800$ & $2,988,500$ \\
\hline Responden 4 & Bandung & 1,900 & 201,474 & 5,399 & 3,387 & 23,400 & $126,336,600$ & $7,925,580$ \\
\hline Responden 5 & Garut & 552 & 15,952 & 187 & 180 & 39,000 & $7,293,000$ & 702,000 \\
\hline Responden 6 & Jakarta & 10,523 & 95,431 & 796 & 918 & 49,500 & $39,402,000$ & $4,544,100$ \\
\hline Responden 7 & Garut & 1,475 & 20,184 & 570 & 346 & 29,800 & $16,986,000$ & $1,031,080$ \\
\hline Responden 8 & Tasikmalaya & 384 & 18,449 & 886 & 347 & 20,000 & $17,720,000$ & 694,000 \\
\hline Responden 9 & Bandung & 2,812 & 17,704 & 375 & 453 & 37,000 & $13,875,000$ & $1,676,100$ \\
\hline Responden 10 & Semarang & 549 & 137,456 & 3,903 & 1,312 & 11,500 & $44,884,500$ & $1,508,800$ \\
\hline Responden 11 & Bandung & 1,561 & 50,854 & 554 & 741 & 117,500 & $65,095,000$ & $8,706,750$ \\
\hline Responden 12 & Bandung & 3,040 & 48,759 & 281 & 1,051 & 55,000 & $15,455,000$ & $5,780,500$ \\
\hline Responden 13 & Bogor & 272 & 527,159 & 415 & 908 & 60,500 & $25,107,500$ & $5,493,400$ \\
\hline Responden 14 & Cimahi & 2,561 & 44,187 & 245 & 560 & 63,000 & $15,435,000$ & $3,528,000$ \\
\hline Responden 15 & Jakarta & 165 & 105,896 & 533 & 560 & 78,000 & $41,574,000$ & $4,368,000$ \\
\hline Responden 16 & Bandung & 65 & 21,067 & 2,501 & 1,014 & 50,000 & $125,050,000$ & $5,070,000$ \\
\hline Responden 17 & Tangerang & 1,750 & 125,978 & 1,657 & 3,222 & 58,000 & $96,106,000$ & $18,687,600$ \\
\hline Responden 18 & Solo & 356 & 49,021 & 204 & 756 & 156,800 & $31,987,200$ & $11,854,080$ \\
\hline Responden 19 & Bantul & 1,887 & 12,476 & 319 & 300 & 57,500 & $18,342,500$ & $1,725,000$ \\
\hline Responden 20 & Solo & 2,832 & 184,465 & 282 & 932 & 91,000 & $25,662,000$ & $8,481,200$ \\
\hline Responden 21 & Batang & 107 & 26,616 & 342 & 348 & 34,000 & $11,628,000$ & $1,183,200$ \\
\hline Responden 22 & Solo & 263 & 21,381 & 218 & 284 & 150,000 & $32,700,000$ & $4,260,000$ \\
\hline Responden 23 & Ciamis & 546 & 5,463 & 8,654 & 200 & 900 & $7,788,600$ & 18,000 \\
\hline Responden 24 & Bandung & 603 & 22,661 & 925 & 568 & 10,000 & $9,250,000$ & 568,000 \\
\hline Responden 25 & Bandung & 672 & 4,763 & 10,593 & 119 & 600 & $6,355,800$ & 7,140 \\
\hline Responden 26 & Surabaya & 235 & 11,882 & 4,779 & 317 & 1,900 & $9,080,100$ & 60,230 \\
\hline Responden 27 & Jakarta & 156 & 15,346 & 250 & 233 & 70,000 & $17,500,000$ & $1,631,000$ \\
\hline Responden 28 & Denpasar & 50 & 8,558 & 213 & 371 & 125,000 & $26,625,000$ & $4,637,500$ \\
\hline Responden 29 & Jakarta & 79 & 129 & 352 & 3 & 16,000 & $5,632,000$ & 4,800 \\
\hline Responden 30 & Cimahi & 450 & 4,361 & 105 & 120 & 55,000 & $5,775,000$ & 660,000 \\
\hline Responden 31 & Surabaya & 56 & 4,349 & 822 & 249 & 26,000 & $21,372,000$ & 647,400 \\
\hline Responden 32 & Surabaya & 27 & 1,875 & 90 & 36 & 100,000 & $9,000,000$ & 360,000 \\
\hline Responden 33 & Jakarta & 736 & 37,562 & 408 & 1,109 & 72,300 & $29,498,400$ & $8,018,070$ \\
\hline Responden 34 & Rembang & 109 & 54,466 & 90 & 18 & 90,000 & $8,100,000$ & 162,000 \\
\hline Responden 35 & Purwakarta & 60 & 94,558 & 432 & 832 & 90,300 & $39,009,600$ & $7,512,960$ \\
\hline Responden 36 & Purwakarta & 270 & 22,671 & 262 & 398 & 99,000 & $25,938,000$ & $3,940,200$ \\
\hline Responden 37 & Bekasi & 95 & 13,151 & 625 & 259 & 13,800 & $8,625,000$ & 357,420 \\
\hline Responden 38 & Garut & 292 & 2,812 & 15 & 43 & 249,000 & $3,735,000$ & $1,070,700$ \\
\hline
\end{tabular}




\begin{tabular}{llrrrrrrr} 
Responden 39 & Bogor & 3,818 & 25,454 & 204 & 560 & 120,000 & $24,480,000$ & $6,720,000$ \\
Responden 40 & Jakarta & 8,077 & 92,217 & 600 & 1,392 & 79,800 & $47,880,000$ & $11,108,160$ \\
Responden 41 & Jakarta & 516 & 52,524 & 405 & 1,074 & 100,000 & $40,500,000$ & $10,740,000$ \\
Responden 42 & Bandung & 1,816 & 53,383 & 285 & 569 & 55,000 & $15,675,000$ & $3,129,500$ \\
Responden 43 & Bandung & 1,481 & 430,406 & 1,430 & 4,220 & 75,000 & $107,250,000$ & $31,650,000$ \\
Responden 44 & Bandung & 1,597 & 46,127 & 401 & 994 & 28,600 & $11,468,600$ & $2,842,840$ \\
Responden 45 & Tangerang & 1,877 & 91,793 & 1,372 & 1,987 & 36,000 & $49,392,000$ & $7,153,200$ \\
Responden 46 & Indramayu & 64 & 20,212 & 1,058 & 409 & 15,000 & $15,870,000$ & 613,500 \\
Responden 47 & Depok & 1,415 & 119,469 & 1,289 & 3,736 & 35,000 & $45,115,000$ & $13,076,000$ \\
Responden 48 & Banyuwangi & 25 & 1,107 & 563 & 12 & 184,000 & $103,592,000$ & 220,800 \\
Responden 49 & Cilegon & 2,043 & 19,212 & 790 & 882 & 10,000 & $7,900,000$ & 882,000 \\
Responden 50 & Yogyakarta & 1,499 & 16,085 & 1,032 & 525 & 14,000 & $14,448,000$ & 735,000 \\
\hline
\end{tabular}

Online shop yang berada di Solo telah memiliki Pelanggan sebanyak 2,832 orang, di Bandung ada yang memiliki Pelanggan sebanyak 3,040, atau di daerah lebih jauh seperti di Jepara 1,643 Pelanggan dan Bantul sebanyak 1,887 Pelanggan. Data ini tercatat sebagai Pelanggan yang telah membeli produk UKMnya melalui online. Angka ini adalah angka pencapaian yang tidak sedikit, dimana para pembeli produk ini tidak pernah bertemu atau bertatap muka sebelumnya dengan Penjual barang dan bahkan Pembeli tidak melihat dengan mata langsung produk yang dibelinya apakah kulitasnya bagus, rasanya enak, apakah pembeli akan tertipu, dsb, hanya melalui online shop.

Dengan adanya situs jual beli online, responden nomor 50 yang berada diwilayah Yogyakarta telah berhasil menambah pelanggannya sebanyak 1,499 dan telah meningkatkan penjualannya diangka Rp14,448,000.

Juga responden lainnya yang mampu memanfaatkan internet dengan melakukan promosi penjualan di situs jual beli online yaitu responden no 4 di wilayah Bandung dimana produk jilbabnya telah dipromosikan di situs jual beli online dan telah berkontribusi mempengaruhidan meningkatkan penjualannya sebesar Rp126,336,600. Reponden 4 telah berhasil menjual produknya sebanyak 5,399 pcs, bahkan produknya telah dilihat sebanyak 201,474 kali dengan Peminat atau calon pembeli sebanyak 3,387 orang. Jika responden 4 mau me-lobby atau rajin untuk menghubungi peminat untuk mau membeli produknya, tidak memungkinkan $10 \%$ saja dari total peminat 3,387 orang maka akan mendapatkan penghasilan tambahan sebesar Rp7,925,580.

\section{E. SIMPULAN}

Hasil penelitian memperlihatkan bahwa terdapat pengaruh yang signifikan untuk penggunaan promosi jual beli online di www.bukalapak.com terhadap peningkatan penjualan produk UKM.

Hal ini dibuktikan dengan hasil dari pengolahan data nilai koefisien korelasi pada penelitian ini adalah 0,75 yang artinya memiliki hubungan yang kuat untuk memperoleh peningkatan penjualan produk UKM. Dan berdasarkan perhitungan statistik, untuk hipotesis penelitian ini yaitu terdapat pengaruh, dengan hasil $t_{\text {hitung }}$ sebesar 9.805 lebih besar dari $t_{\text {tabel }}$ yaitu 1.677 , atau dengan kriteria penilaian $t_{\text {hitung }}$ $>t_{\text {tabel }}$ maka $\mathrm{H}_{0}$ ditolak dan $\mathrm{H}_{1}$ diterima (berpengaruh). 


\section{DAFTAR PUSTAKA}

Alexander, Y. (2002). Enabling E-Commerce Growth Through The Social Construction Of A Virtual Community's Culture. Journal of Electronic Commerce Research, VOL. 3, NO. 4, 279.

Alma, B. (2006). Pemasaran dan Pemasaran Jasa. Bandung: Alfabeta.

Armaat, S. C. (2007). Discovering Computers: Menjelajah Dunia Komputer Fundamental Edisi 3. Jakarta: Infotek Salemba.

H. Djaslim Saladin dan Yevis Marty Oesman. (2002). Intisari Pemasaran dan Unsur-unsur Pemasaran. Bandung: Cetakan Ke Dua, Linda Karya .

Hafsah, M. (2004). Upaya Pengembangan Usaha Kecil dan Menengah (UKM). Jurnal Infokop Nomor 25 Tahun XX.

Jansen, B. (2006). An Examination Of Searcher's Perceptions Of Nonsponsored And Sponsored Links During E-commerce Web Searching. Journal Of The American Society For Information Science And Technology, 57(14):1949_ 1961.

Jonathan dan Prihartono. (2012). Perdagangan Online Cara Bisnis di Internet. Elex Media.

Kuncoro, M. (2008). Tujuh Tantangan UKM di Tengah Krisis Global. Harian Bisnis Indonesia.

Pearson, M. (2008). Sistem Informasi Manajemen. Jakarta: Salemba.

Sripo. (2010). 38.044 UKM Serap 163.830 Tenaga Kerja. Harian Umum Sriwijaya Post Tanggal 15 April 2010.

Sugiyono. (2012). Metode Penelitian Bisnis. Bandung: Alfabeta.

Supardi, J. (2009). Rancang Bangun Collaborative System Pemasaran Hotel Secara on-line Dengan Pendekatan Mediator based. Jurnal Sistem Informasi Fasilkom Unsri Vol 1 No 2.

Swastha, Busu, dan Irawan. (1997). Manajemen Pemasaran Modern. Yogyakarta: Liberty.

Situs Internet:

- $\quad$ https://m.tempo.co/read/news/2016/05/04/173768481/bps

- $\quad$ https://www.wearesocial.sg.2015

- $\quad$ https://www.apjii.or.id/

- $\quad$ http://www.cnnindonesia.com/teknologi/20161126172041-185-

175520/revisi-uu-ite

- $\quad$ http://news.metrotvnews.com/peristiwa/yNLQwM1b-seluruh-pelosoknegeri-terjangkau-internet-pada-2019 